\title{
Reforming the Affordable Care Act
}

David Colander

Middlebury College, Middlebury, Vermont 05753, USA.

Eastern Economic Journal (2017) 43, 173-179. doi:10.1057/s41302-016-0078-6; published online 16 November 2016

The U.S. health care system is a mess, and the Affordable Health Care Act (ACA) has made it more of a mess. ${ }^{1}$ While the Affordable Health Care Act's goals are laudable, and, as part of a process of providing reasonable health care at reasonable costs to all Americans, it is good that it passed, the Act should best be seen as a step in the process of health care reform, not as the desired end state. The Act's primary redeeming feature is that it conveys a recognition that the entire U.S. health care system is broken and it needs to be reformed.

A central problem with the ACA is that it tries to deal with the U.S. health care problem as an insurance problem, when in fact the fundamental problem with the U.S. health care system is a cost and accessibility problem. Health care in the U.S. costs way too much; reasonable health care at reasonable costs is not accessible or affordable for a large portion of the public, even though it could be. ${ }^{2}$ The fact that some Americans do not have health insurance is not the central problem. In fact, an important reason why the U.S. health care system costs too much is because too many Americans have the wrong type of health insurance. Seeing the U.S. health care problem as an insurance problem, rather than as a cost and accessibility problem, worsens the cost problem while doing little to help the accessibility problem.

The argument for seeing the health care problem as an insurance problem goes as follows: People do not have health insurance, so if we can provide affordable health care insurance to all, we can "solve" the health care problem. The ACA tried to do that. It created health insurance exchanges to provide health insurance to all at prices individuals could afford. Since many people do not earn enough income to afford the insurance, the Act subsidized health insurance for them, expanding the number of people that have health insurance.

On a superficial level the above argument sounds good. But dig under the surface, and one uncovers a fatal flaw. The flaw is that, at the existing bloated costs of health care, we, as individuals, and/or as a society, are not willing to pay for everyone to have access to that bloated-cost health care, nor are we willing to pay for the health insurance needed to pay for it. The real health care problem in the U.S. is that health care costs too much. The result is that health insurance costs too much as well. We pay for our current system only because the costs are hidden in a morass of cost accounting sleights of hand, subsidies, and implicit taxes that make it close to impossible to figure out who is actually paying what. 


\section{HOW TO MOVE FORWARD}

Economists know how to hold down costs: Design the health care system so that it follows the golden rule of economics: Him who pays makes the rules. Costs of health care will be contained only if they are directly connected to what the person or organization paying for that health care is paying. That means that if government pays, experts appointed by government decide what health care will be available to individuals, and how much government will pay for it. If individuals pay, then individuals decide; if insurance companies pay, then insurance companies decide. The US health care system is an unmanageable blend of all three of these in which who decides and who pays are largely disconnected.

Sophisticated progressives who championed the ACA understood the golden rule of economics; they recognized that the ACA would make the health care system more of a mess. They supported it nonetheless because (1) they believed it would improve accessibility for some low-income individuals, and (2) they saw it as a path to a government single-payer system in which medical costs were financed by general government revenue. They believed that if (1) government were the single primary payer for health care; (2) there was a board of experts who decided what health care people would get; and (3) government could bargain with providers to hold costs down; eventually the changes brought about by the ACA would lead to a reasonably efficient and fair health care system. Once that happened, total costs of our health care system would be reduced and medical care would be more accessible to poor people than it is now. They based this belief on the fact that some version of a single-payer system is used by most advanced countries, and, in terms of holding down costs, and providing broad access to medical care for all, these systems work much more efficiently than the current U.S. system, albeit with many well-known problems. ${ }^{3}$

The second way of holding down health care costs is what is sometimes called the market solution, but a better name for it, which contrasts it with the single-payer system, is a multi-payer system. Like the single-payer plan, a multi-payer plan meets the golden rule of economics. The difference is that the main source of cost control comes from individuals because it is individuals, not government, who are paying, and it is individuals, not government, who are making decisions about what type and how much health care to consume. In a multi-payer health care system, the majority of individuals pay for their own health care, either directly, or indirectly through insurance that they buy and pay for.

I do not like to call a multi-payer health care system a "market system," because health care is not a normal market good. There are two reasons why. First, unlike most goods, society sees everyone as having a right to a minimum level of health care regardless of income. That decision means that the distribution of health care cannot be left solely to the market. A second reason is that any reasonable multi-payer system will have many non-market attributes because health care consumers often lack the information, and know they lack the information, needed to make reasonable health care decisions. An unregulated market system where medical care providers are primarily concerned with monetary profit, not with providing quality health care at affordable prices, is not a reasonable system since it leaves many susceptible to snake-oil medicine. Thus, any realistic multi-payer system will involve an important role for government, non-profit, and for-benefit provision or subsidization of health care to some portion of the population. ${ }^{4}$ The policy debate is not about market versus government provision. The debate is about whether the central institutional structure emphasizes bottom-up consumer control, or top-down government control. 
Currently, the U.S. is on a path to a single-payer system, not because that makes the most sense, but because the current U.S. health care system is structured in a way to essentially make it impossible for a multi-payer system in health care to work. The reason is that a reasonable multi-payer system requires (1) consumer cost transparency of both medical care and medical insurance, and (2) relatively equal bargaining power for all consumers. Our current system has neither. A reasonable multi-payer system requires that the price charged individuals for medical care and health insurance reflects the economic cost of providing that care and insurance. Our current system does not do that. Instead, it obscures costs of both health care and insurance in ways that are strongly biased against a multi-payer system.

\section{REMOVING THE BIAS AGAINST A MULTI-PAYER SYSTEM}

Perhaps the best way to explain the bias in the present system is to explore two laws designed to modify the existing reimbursement and pricing regulations in a way that would reduce the current implicit bias against a multi-payer system. The central goal of the two laws is transparency; they make it more likely that prices charged individual for health care and health care insurance reflect the economic costs of providing that care and insurance.

The two laws are in no way sufficient to create a reasonable multi-payer plan. They should be seen as stepping stones that would create more of a level playing field on which to judge the desirability of a multi-payer health care system. If we were to actually move to a multi-payer plan many other changes would be needed, such as changes in drug patent policy, drug advertising policy, regulatory restrictions on entry into health care, the nature of regulation of the health care industry, and liability laws, among many others.

\section{THE FAIR HEATH CARE PRICING LAW}

The first law is the following:

- Individuals paying for their own health care will pay no more than the price paid for the equivalent health care by large insurance companies or by government. ${ }^{5}$

To explain the need for this law you need to know how the system works now, and how a multi-payer system is designed to work. Currently, what a person is charged for medical care depends on his or her bargaining power, not what they would be charged in a reasonably functioning multi-payer market. Medicaid, which has significant bargaining power, might pay $\$ 1200$ for a procedure while someone who is paying for the same procedure out of their own pocket with no bargaining power, would have to pay $\$ 12,000$.

Another example might involve a three-day hospital stay. The bill for this stay might say it cost $\$ 20,000$, but what will actually be paid depends on who is paying it. Your insurance company might pay $\$ 4000$; the government Medicaid system might pay $\$ 3000$; an individual with no insurance, but who negotiated payment beforehand might pay \$3500; an individual with no insurance who did not negotiate beforehand might pay $\$ 20,000$; an individual with no insurance and no income might be charged $\$ 20,000$ but actually pay nothing, since it is the duty of hospitals to provide needed medical care for people regardless of their income. ${ }^{6}$ These varying prices are representative of the way pricing works in today's health care system; they capture the reality that if you are paying yourself, you will generally be charged the highest rate, while, the government and big insurance companies, because of their strong bargaining power, get large discounts and 
often pay the lowest rates. The proposed regulation would change that. The proposed change would make it so that an individual with no insurance would pay no more than the government and large insurance companies pay.

In thinking about these many different prices paid by individuals, someone who has only had a principles course in economics might think that the differences in prices are unfair and represent a lack of competition. That is not true. In upper level economics courses, one learns that industries such as health care do not fit the principles story of market pricing. In medical care markets, (and in an increasing number of other markets), the provider's costs are dominated by lumpy, joint overhead costs, making the marginal costs focused on in principles courses only a small part of the actual costs. Thus what it "costs" to produce such a good will differ among users depending on how the cost accounting system is used to allocate overhead to different users.

It is in assigning these overhead costs that our current system of health care cost accounting methods does not replicate an economically efficient cost accounting system. Specifically, the current system of cost accounting leads health care providers to assign far more overhead to poor and middle-income individuals paying for their own health care than those individuals would be assigned in a well-functioning multi-payer system where all had equal bargaining power. In a well-functioning multi-payer system, overheard costs would be allocated by what economists call an inverse demand elasticity Ramsey rule. This rule assigns almost all of the overhead costs to final users who can, and will, pay the most, while others pay very little of the overhead. In multi-payer markets, those who can, and will, pay, are generally the rich, so using the Ramsey rule, the rich cover most of the overhead costs of health care, while the poor pay primarily incremental costs.

For many goods, the private market does a reasonable job of directing firms toward that Ramsey rule pricing structure. Airlines have cheap seats that cover marginal costs, and expensive seats that pay much of the overhead. Internet companies provide free Apps whose costs are covered by advertising, and expensive premium versions that cover most of the overhead. Walmart provides basic shirts at close to incremental costs, and Brook Brothers provides luxury shirts at luxury prices. In many ways, the effects of the Ramsey rule pricing is the beauty of a market system, as Joseph Schumpeter noted long ago when he wrote "The capitalist achievement does not typically consist in providing more silk stockings for queens but in bringing them within reach of factory girls." If providers were using the Ramsey rule to assign overhead costs, and people were paying for their own medical care, the rich would pay most of the overhead, and the poor would pay almost none.

In our current health care market, the Ramsey rule for maximizing social welfare does not assign most overhead to the rich because (1) payments for much of health care are not made by individuals, but rather by third party payers - insurance companies and government - that face regulatory, political, and institutional rules governing payments, and (2) medical reimbursement is governed by a myriad of complex regulations about the care provided and what providers can charge for that care. The result is that, instead of overhead being allocated to the richest and most willing to pay users, overhead is allocated to take advantage of the regulatory rules, and according to the bargaining power of the organization paying. In that process, perversely, the poor and middle class who pay the costs themselves end up paying a higher percentage of the overhead costs than the rich. It is that perverseness that the proposed law is designed to offset.

For example, consider a low-income individual with no insurance as in the example above. Following the inverse elasticity rule, he would have little overhead assigned to him. But in the current system that person would have a large amount of overhead 
assigned, and expected to pay, $\$ 20,000$. The hospital recognizes that if the person is poor, such charges might push him into bankruptcy, which means the hospital will not be paid. But even in this case, under current regulations it makes sense to bill the person for $\$ 20,000$. The reason is that hospitals get partially reimbursed for medical care provided to those who cannot afford it, so the hospital has an incentive to charge as high a reimbursement as it can to maximize this partial reimbursement. Say for example, that the hospital gets reimbursed $20 \%$ of the cost of treating those who cannot afford it. If they charge $\$ 20,000$, they are reimbursed $\$ 4000$; if they charge only $\$ 1000$, they are reimbursed $\$ 200$.

The above example shows how, because of the perverse overhead cost allocation, poor and middle-income individuals without insurance who are paying for their own medical care, can end up subsidizing the rich, the well-insured, and the poor covered by government health plans. That undermines the multi-payer system and keeps it from operating and expanding, and pushes toward a single-payer system. The proposed law will change that. The result of the law will be that much more of the overhead will be paid by the rich, their insurance companies, and the government, and less by individuals paying for their own health care.

\section{THE FAIR HEALTH INSURANCE PRICING LAW}

The second law relates to the pricing of insurance. I call it the Fair Health Insurance Pricing Law. It states:

- Individual should not be required by government regulation to pay more than the actuarial cost of their health insurance.

To understand the reasoning for the law, it is useful to consider the role of insurance in economic theory and the way in which current government regulations prevent insurance companies from pricing insurance at its actuarial costs (the expected costs of a person's medical care, given their health characteristics). Insurance provides a way for individuals to spread the risk caused by random harmful events. The underlying theory is relatively straightforward and is centered on actuarial costs. Say that there is a 1/10000th actuarial chance that you might have an accident requiring medical care, and if you do, that care will cost $\$ 100,000$. The actuarial cost of that medical care will be $\$ 10$. Insurance lets consumers pay the actuarial costs (plus an administrative fee) beforehand, and then if the event occurs, the consumer gets the $\$ 100,000$ paid for by the insurance. Put another way, the purpose of insurance is to transfer randomly occurring medical care costs into actuarial costs of the medical care, and in doing so, spread the risk.

For an insurance market to operate efficiently and fairly, each person insured needs to be charged his or her actuarial costs. These can differ significantly among individuals. For example, older people have much higher actuarial costs of health care than do younger people, and physically fit people have much lower costs than do those who are not physically fit. A transparent actuarial cost health insurance system would have drastically different prices of insurance for different individuals - physically fit young individuals would be charged a low price, and out-of-shape, older people would be charged a much higher price. ${ }^{7}$ Those with preexisting conditions would be charged an astronomical price. For insurance to serve its market purpose, insurance companies would be free to divide up groups into their best estimate of the appropriate actuarial groupings and charge each group accordingly.

Because our society believes that all individuals have a right to health care regardless of their actuarial costs, or their income, the multi-payer plan cannot be relied upon to 
provide either health care or health care insurance for everyone. Government has a role to play in any reasonable multi-payer plan. Specifically, government must step in either to provide direct health care or subsidized health insurance for those who cannot afford their actuarial costs of insurance. The question the proposed law addresses is not: Should government subsidize health care or health care insurance to those who cannot afford it? It accepts that government should and will do so. The question this law addresses is: Will the government be transparent in what that subsidy is?

In the current system, regulatory restrictions prevent insurance companies from charging actuarial prices to individuals. Instead, insurance companies are required to charge all people the same price regardless of actuarial costs. Essentially, what current regulations do is to place a hidden tax on actuarial low-cost individuals which is then used to subsidize the cost of actuarial high-cost individuals. For many young, poor, and middle-class healthy individuals, currently receiving government subsidies for health care insurance, this hidden tax is actually greater than the subsidy they receive, which is one reason why many opt out. Given this tax, in the current system we have some rich unhealthy individuals being subsidized by poor and middle-class healthy individuals, even though it looks as if those poor and middle-class individuals are being subsidized by government. $^{8}$

The proposed law would eliminate the hidden tax. The ACA subsidies would evolve from subsidies based on income, to subsidies based on a combination of income and risk characteristics and health care costs would be more transparent. Many more healthy individuals would choose to buy health insurance for catastrophic accidents and illness (and could reasonably be required to do so since they are no longer facing a hidden tax). They will pay the majority of their own health care costs, putting downward pressure on costs. Rich, unhealthy people would likely be charged a lot more for their health insurance and their medical care. In response, they too will put downward pressure on costs.

The government will still need to subsidize those who cannot afford medical insurance either because of income or their high actuarial costs. But those subsidies would now be transparent, which would encourage government to figure out alternative health care delivery mechanisms, such as HMOs and direct government provision, for this subgroup of individuals. With transparent costs, the majority of individuals could have health care provided to them in a working multi-payer system in which individuals both pay and decide what health care they want.

\section{A FINAL COMMENT}

I am a realist and recognize that the chances of these two laws being passed are not high. But the plans are nonetheless worth considering, and advocating, because they provide a needed theoretical foundation within which one can think about how to develop a reasonable and fair multi-payer system in which health care is accessible to all. The two laws highlight the unfairness of the current system in a way that will resonate with many individuals. To have poor and middle-class individuals without insurance subsidizing health care costs of rich individuals with insurance is unfair. To have poor and middleclass young healthy individuals subsidizing the insurance premiums of rich older individuals who can afford to pay more is similarly unfair. But that is what our current system does. Advocating these two laws would bring those unfairnesses to the fore, and direct the policy debate about health care towards cost transparency, a debate where the benefits of the multi-payer plan become apparent. 


\section{Notes}

1. The ACA is often called ObamaCare. This column assumes a basic knowledge of the provisions of the ACA. For those who would like an introduction to the provisions of the ACA, they might explore http:// obamacarefacts.com/obamacare-facts/, or http://www.hhs.gov/healthcare/facts-and-features/key-features-ofaca/.

2. Health care as a percent of GDP is $17-18 \%$ in the U.S. and $10-11 \%$ in most developed European countries.

3. A primary problem of single-payer systems is its costs. For the U.S., a single-payer system would require about $\$ 1.5$ trillion dollars in additional tax revenues a year if it included a strong board of experts who could limit expenditures without facing serious political repercussions, and government used its power to hold down costs. Costs would go up significantly higher without that strong board of experts having the power to make decisions on the health care provided.

4. Just like a multi-payer plan includes government-provided elements, so too does a single-payer plan include market-provided elements. For example, any real-world single-payer system allows for supplemental private insurance and supplemental private medical care, which individuals pay for themselves. So a single-payer system does not preclude individual pay/individual decide health care. It simply says that government will not pay for it.

5. A corollary to this law would eliminate co-pay reductions for individuals given by drug companies. These co-pay reductions create perverse incentives, making it advantageous for individuals to use a higher-priced drug, even when it would make far more sense to use a lower-priced drug.

6. There are many more dimensions of payment obfuscation and non-transparency, and a person will likely receive many different bills for a hospital stay, not a consolidated bill.

7. In practice, groups of individuals would be provided with different costs. $30 \%$ of the population - the young and the healthy-might fall into a low cost pool with very low actuarial costs. $50 \%$ might fall into a normal risk pool with average actuarial costs, $15 \%$ of the population might fall in a high risk pool, and with very high actuarial costs, and 5\% might fall into a super high risk pool; with an astronomical actuarial cost.

8. If individuals were changed their actuarial costs of health insurance, the ACA's mandate would make much more sense; it would serve its purpose, not be a hidden tax forced on the working poor. 